EDITORIAL

\title{
A REGIONAL ORGANIZATION FOR SEDIMENTARY GEOLOGY
}

Early this year DR. GERALD M. FRIEDMAN of the RENSSELAER POLYTECHNIC INSTITUTE prepared a petition for presentation to the council of the SOCIETY OF ECONOMIC PALEONTOLOGISTS AND MINERALOGISTS, an organization most active in encouraging and publishing sedimentary and paleontological research work. This petition, signed by about 50 members of the organization who were present at the Philadelphia meeting of the Northeastern Section of the Geological Society of America in February, 1966, requested the council to allow the formation of an Eastern Section of S.E.P.M. This was approved at the meeting of the S.E.P.M. council at St. Louis in April, who requested those sponsoring the section to form an executive committee and submit a constitution to the national office of S.E.P.M. official approval for the proposal was received at the end of May, signed by all members of the national executive committee. There, for the moment, the matter stands, and it is up to interested sedimentologists and paleontologists in this region to develop it from this stage.

The following recommendations are offered by the Editor in a personal capacity, as an interested research worker; however, they express ideas held, partly or wholly, by a number of other geologists involved in the region. It is proposed that the Eastern Section of S.E.P.M. should be characterized by the following:

(i) the area of concern should be the Northern Appalachians from Pennsylvania to Newfoundland, extending westward to include New York State and southern Ontario and Quebec; political boundaries should not influence the section's scope.

(ii) the main object of the section should be to promote field meetings and seminars at significant points in the region so that specialists and others may have the best opportunities for seeing research work of fellow scientists. The organization should eventually produce a result not unlike that of the Geologists' Association in Britain, which has an impressive annual offering of well-organized field meetings ranging from half-day to three weeks in duration. The Eastern Section could begin by co-ordinating those specialist field meetings that already take place as ad hoc events (e.g. Gaspé, Five Islands trips this year - the latter reported on page 150 in this issue), and proceed to encourage a small number of similar ones - preferably in adjacent areas on adjacent dates. These are envisioned as specialist meetings with a limit on participation, not competing with larger events such as the New England Intercollegiate Geological Conference.

(iii) an annual convention should not form part of the section program; this function is already well taken care of by the Northeastern Section of the Geological Society of America.

(iv) one or more seminars or group discussions should be arranged annually, sponsored by a university or research institution and utilizing 
several invited participants to examine thoroughly the research work being done on one or more selected topics. These meetings may, of course, be carried on in the field, or in conjunction with field trips.

(v) an important and potentially rewarding function of the section could be the sponsorship of student field trips in various parts of the region. This would be preferable in many respects to encouraging students to join the specialist trips. Organization of effective trips to many important areas is beyond the capability of most universities, and students on Section-sponsored trips would benefit from contact both with research workers and their contemporaries from other universities.

(vi) while it is to be expected that Maritime Sediments will be useful as a channel of communication of the Eastern Section of the S.E.P.M., we are opposed to any organic link being made between this journal and the proposed Section. Quite apart from the somewhat different geographical scope and other divergences, this journal values its independence in matters such as policy and staff.

Readers who are concerned for the development of the Eastern Section of S.E.P.M. along these or any other lines are encouraged to formulate their ideas and let them be known. It is suggested that these should be submitted sometime soon to one of the following:

DR. GERALD M. FRIEDMAN, Rensselaer Polytechnic Institute, Troy, N.Y.;

DR. GERARD V. MIDDLETON, McMaster University, Hamilton, Ontario;

DR. GEORGE deVRIES KLEIN, University of Pennsylvania, Philadelphia, Pa.;

DR. DERYCK J.C. LAMING, University of New Brunswick, Fredericton, N.B.

Those wishing to make their views public are invited to address correspondence to the Editor of Maritime Sediments (please mark "for publication"). If sufficient response has been made before November, organization of the section may get under way quite shortly. Further progress will hopefully be reported in the October issue of this journal.

A draft version of this editorial was shown to a few people, and the following responses were received up to press time:

From DR. GERARD V. MIDDLETON :

"Thank you for letting me see the draft version. It has my wholehearted support on practically every point. The Eastern Section of the S.E.P.M. will have a membership substantially different in character from the strongly industry-based Pacific, Gulf Coast and Permian Basin Sections, and for this reason it will have to work out a program for itself with little precendent to guide it.

"It seems clear to me that there are more than enough conventions to satisfy even the most insatiable appetites for talk, but there is a real need for an organization which will run field trips and co-ordinate those run locally. In my opinion, these should be of two main types: (i) regional field trips, designed to be of general 
interest and to explore the sedimentological and paleontological features of a particular region; and (ii) specialist field trips, designed to explore specific research problems in the field and to promote contact between research workers interested in these problems. The Gaspe trip which was run this spring is an example of the latter type."

From DR. GEORGE deVRIES KLEIN:

\begin{abstract}
"Your editorial has my full support. The idea of student field trips is unique, and deserves both close attention and immediate implementation.
\end{abstract}

\begin{abstract}
"As for an annual convention (reference to your item (iii)) the Eastern Section of S.E.P.M. should explore the possibility of organizing sedimentological and paleontological programs as part of the general program of the Annual Meeting of the Northeastern Section of the Geological Society of America, in much the same way that the annual S.E.P.M. meetings are held in conjunction with the A.A.P.G. Such a step, however, should receive approval from national headquarters of both S.E.P.M. and G.S.A., as well as the Northeastern Section of the G.S.A."
\end{abstract}

DR. GERALD M. FRIEDMAN commented that most of the proposals were very good. He was somewhat critical of the suggestion of a limit on participation in specialist field meetings, mentioned in item (ii), wishing to see no discrimination (many field trips have a limit placed on the numbers that can attend - Ed.); he also thought that Washington would form a better southern limit to the area than Pennsylvania (item (i)). As a longtime member of the Geologists' Association, he was not sure that it, basically an amateur organization, provided a good analogue to the intended section: the Permian Basin Section of S.E.P.M. is more comparable. However, he agreed that the G.A. program of field meetings offered a good example of the type of activity desired.

Dr. Friedman pointed out that reports of activity of the various sections of S.E.P.M. are given annually in the June issue of the Journal of Sedimentary Petrology and the July issue of the Journal of Paleontology. Reports from the Eastern Section, when formed, would appear together with those of other sections in these journals.

From DR. JAMES R. BEERBOWER :

"I should like to indicate my enthusiastic support for the idea and for the several activities proposed for the organization. The seminars for Eastern Canadian paleontologists begun two years ago at McGill provide, I believe, an encouraging and successful analogue for such an organization. The field meeting-seminar concept is a very worthy one, much more fertile than an annual formal meeting. There are at least two projects afoot for such trips in the next year that I know of - one on alluvial sedimentation and stratigraphy planned by PETER BUTTNER from Rochester, the other on Middle and Late Devonian paleoecology of New York to be undertaken jointly by MCMASTER, ROCHESTER and YALE." 